\title{
Impact of Kaolinite Clay Particles on the Filtration of Cryptosporidium-sized Microspheres
}

\author{
Isabelle Papineau ${ }^{l, *}$, Nathalie Tufenkji ${ }^{2}$ and Benoit Barbeau ${ }^{I}$
}

${ }^{1}$ Industrial NSERC Chair on Drinking Water, Department of Civil, Geological and Mining Engineering, Ecole Polytechnique de Montreal, P.O. Box 6079, Downtown Station, Montreal, Quebec, Canada, H3C 3A7.

${ }^{2}$ Department of Chemical Engineering, McGill University, 3610 University Street, Montreal, Quebec, Canada, H3A 2B2.

${ }^{*}$ Corresponding author

Tel.: 1.514.340.4711x3727; Fax: 1.514.340.5918; E-mail: isabelle.papineau@polymtl.ca 


\begin{abstract}
Granular filtration remains a key barrier for Cryptosporidium removal in water treatment plants without UV irradiation. To assess the impact of clay particles in source water on Cryptosporidium removal efficiency by granular filtration, this study investigated the cotransport of Cryptosporidium-sized microspheres and kaolinite particles in sand columns. To investigate the influence of clay load on microsphere transport and deposition, varying influent kaolinite concentrations (0 to $10^{6}$ particles $/ \mathrm{mL}$ ) and microsphere concentrations $\left(10^{2}\right.$ to $10^{6}$ microspheres $\left./ \mathrm{mL}\right)$ were tested. The spatial distribution of retained microspheres was examined subsequent to experiments via filter coring. Results demonstrate that increasing the influent microsphere concentration impaired filter performance due to a blocking mechanism whereby previously retained particles repel incoming particles. In contrast, when the particulate load was dominated by kaolinite (for an equivalent particulate load), filter performance improved as a result of filter ripening whereby previously deposited particles act as additional collectors. Thus, microsphere-kaolinite interactions proved to be favorable although both particles possessed negative zeta potentials in the tested conditions. This study demonstrates that granular filter performance is vulnerable to peak events of microbial contamination. Conversely, Cryptosporidium-sized microsphere removal by granular filtration is enhanced in the presence of kaolinite in source water.
\end{abstract}

Keywords: Clay; Cryptosporidium; filtration; kaolinite; microsphere; water treatment 


\section{Introduction}

The seasonal variations of Cryptosporidium occurrence in surface waters is proven to be watershed specific, with peak concentrations associated to rainfall or snowmelt events which lead to increased river flow, combined sewage overflow, and/or agricultural runoff (World Health Organization 2006). These extreme events are of sanitary concern as the seasonality of cryptosporidiosis cases is related to seasonal variables such as temperature, precipitation and river flow (Lake et al. 2005). Peak concentrations of naturally occurring clay particles in surface waters may also result from sediment resuspension due to increased river flow and surface runoff subsequent to rainfall or snowmelt (Gaskin et al. 2003; Gauthier et al. 2003). Interestingly, Cryptosporidium oocysts have been shown to attach to kaolinite (clay) particles when suspended in the water column which enhances the oocyst settling velocity and favors oocyst deposition in stream beds (Searcy et al. 2005). Such a phenomenon may also impact performance of granular media filters used for the production of drinking water. This research question is of significance as water treatment plants (WTPs) without UV irradiation or membrane filtration will typically rely on granular media filtration as the principal barrier for Cryptosporidium removal.

Microbial transport in granular media is influenced by (i) particle-particle interactions and (ii) influent microbe/surrogate concentrations as they both will result in timedependent removal mechanisms such as blocking, straining (Bradford \& Bettahar 2006) and ripening (Camesano \& Logan 1998). Blocking occurs in the presence of unfavorable particle-particle interactions where the previously deposited particles shield a portion of the grain and repulsion is experienced between the deposited and suspended particles of the same nature (Ryan \& Elimelech 1996). Consequently, this mechanism impairs filter performance and occurs to greater extent at higher influent particle concentrations (Camesano \& Logan 1998; Bradford \& Bettahar 2006). In contrast, filter performance may be improved by straining when larger particles are retained by physical exclusion at pore throats (Bradford \& Bettahar 2006; Bradford et al. 2006). Moreover, filter performance may be improved by ripening when particle-particle interactions are favorable (Camesano \& Logan 1998) as the previously deposited particles behave as additional collectors and favor particle deposition (Yao et al. 1971). Media ripening has also been attributed to inorganic particles such as clay which are naturally present in surface waters (Gitis et al. 2002).

Suspended clay minerals can influence microbial transport in porous media. In fact, previous studies have provided evidence that the attachment of viruses (Chrysikopoulos \& Syngouna 2012), bacteria (Vasiliadou \& Chrysikopoulos 2011) and protozoa (Park et al. 2012) onto collector grains was facilitated by the co-transport of clay minerals and biocolloids. Specifically, increased deposition of Cryptosporidium onto quartz sand was observed when co-injected with illite clay (Park et al. 2012). Similar observations were made in batch reactors where minimal Cryptosporidium attachment occurred onto sand grains in the absence of clay particles but deposition improved in the presence of kaolinite due to oocyst attachment to the previously deposited clay particles (Gitis et al. 2002). Nonetheless, it is unclear to what extent the kaolinite-oocyst interaction leads to improved oocyst removal by granular media filters in engineered systems such as rapid 
granular media filters. The impact of oocyst-kaolinite co-transport on treatment performance in engineered filters may differ considerably from reported observations made in well-controlled bench-scale packed columns because engineered filters use coarser and more heterogeneous media and are operated at higher flow rates. In this context, it is also unknown how granular filtration performance may vary with a change in suspended clay concentration, and particularly, when exposed to typical natural clay loads in surface waters.

The objective of this investigation is to characterize Cryptosporidium-sized microsphere transport and deposition in rapid sand filters under varying influent microsphere and clay (kaolinite) concentrations. Polystyrene microspheres have been reported to be a conservative surrogate for Cryptosporidium in column and in pilot scale experiments (Emelko et al. 2005). Lab-scale rapid sand filtration experiments were conducted in the absence of a coagulant, to assess the co-transport behavior of microspheres and kaolinite particles independently of coagulation/flocculation. These conditions were selected to mimic the direct filtration (without coagulation) WTPs currently operated in Montreal (Canada) to provide drinking water to 1.6 million people. Microsphere breakthrough curves and retention profiles were evaluated to assess the mechanisms that influence microsphere deposition for various loads of influent microspheres and kaolinite.

\section{Materials and methods}

\section{Cryptosporidium-sized Microspheres}

Fluoresbrite ${ }^{\circledR}$ yellow green carboxylated polystyrene microspheres (Polysciences Inc., USA) of a diameter of $4.358 \mu \mathrm{m}( \pm 0.113)$ and a density of $1.05 \mathrm{~g} / \mathrm{mL}$ were selected as a surrogate for Cryptosporidium. Although microspheres were proven to be conservative surrogates for Cryptosporidium (Emelko et al. 2005), they lack surface proteins that have been shown to drive the electrosteric repulsion between oocysts and collector grains (Tufenkji et al. 2006). Therefore, in some conditions, microsphere and Cryptosporidium retention behavior might differ according to oocyst physiological conditions (e.g. age, viability, exposure to environmental stresses, etc.) which influence surface protein structure and consequently the extent of electrosteric repulsion between Cryptosporidium and collectors (Tufenkji et al. 2006). Prior to filtration experiments, the microsphere suspension was vortexed, diluted in synthetic water and agitated with a stir bar. The synthetic water used to carry out experiments was created to mimic the mineral composition of the St. Lawrence River $(\mathrm{pH}=8.2 \pm 0.07$, ionic strength $=4.37 \mathrm{mM})$. The chemical composition and the measured physico-chemical properties of this synthetic water are listed in Supplementary Information (Tables S1 and S2). For microsphere enumeration, suspensions were filtered on $2.0 \mu \mathrm{m}$ porosity filters and then enumerated by laser scanning cytometry (ScanRDI, AES Chemunex) and confirmed by epifluorescence microscopy at a magnification of $600 \times$ (BX-60, Olympus) using an Olympus U-MWIBA filter. 


\section{Kaolinite clay suspension}

A clay suspension was chosen to represent the total suspended solids of the St. Lawrence River which are mostly of a mineral nature ( $73 \%$ to $81 \%$ ) (Gauthier et al. 2003). Kaolinite (specific gravity of 2.6) was selected as representative clay in this investigation. Kaolinite was hydrated in Milli-Q water, agitated $(24 \mathrm{~h})$ and sonicated in a low intensity bath (30 min.) to obtain a particle size distribution representative of the St. Lawrence River $(95 \%$ of particles $<5 \mu \mathrm{m})$ (Caron et al. 2007) which was validated by a Dynamic Particle Analyzer (Brightwell Technologies). The suspension was then diluted using synthetic water to obtain the desired kaolinite particulate load prior to the addition of microspheres.

\section{Electrokinetic properties of Cryptosporidium-sized microspheres and of kaolinite}

The electrophoretic mobilities of microspheres and kaolinite particles were measured in synthetic water $\left(20^{\circ} \mathrm{C}, \mathrm{pH}=8.2\right)$ using a Zetasizer Nano (Malvern) and were converted to zeta potentials using the Smoluchowski approximation. The calculated zeta potentials were determined to be $-41.4 \pm 0.7 \mathrm{mV}$ for microspheres and $-22.6 \pm 1.0 \mathrm{mV}$ for kaolinite.

\section{Filtration experiments and column set-up}

The design/operational conditions (e.g., filtration rate) of the experimental set-up were chosen to reproduce the Atwater and Charles-J. Des Baillets WTPs (Montreal, Canada) which are fed by the St. Lawrence River. Filtration experiments were conducted with duplicate sand filters (depth of $74 \mathrm{~cm}$ ) in PVC columns (inner diameter of $32 \mathrm{~mm}$ ) operated at a filtration rate of $5 \mathrm{~m} / \mathrm{hr}$. The chosen silica sand (Temisca Inc., Canada) possessed an effective size $\left(d_{10}\right)$ of $650 \mu \mathrm{m}$, a median size $\left(d_{50}\right)$ of $860 \mu \mathrm{m}$ and a uniformity coefficient (UC) of 1.4 . Moreover, its density and porosity were $2.53 \mathrm{~g} / \mathrm{cm}^{3}$ and 0.35 , respectively.

Prior to an experiment, a column filled with new media was backwashed at a target of $40 \%$ bed expansion, and flushed $(1 \mathrm{~h})$ with a microsphere-free synthetic water to allow media pre-conditioning. During filtration experiments, the microsphere and kaolinite injection was conducted over 20 pore volumes (PVs) after which the column was eluted for $12 \mathrm{PVs}$ with a microsphere and particle-free synthetic water. Influent samples were collected at 3, 7, 11, and 15 PVs and column effluent samples at every PV throughout the filtration experiment.

To assess the impact of surface water clay concentration on Cryptosporidium removal by filtration, the microsphere and kaolinite content of the influent water were adjusted according to the experimental design summarized in Table 1. The range of total particulate loads tested was selected to be representative of typical particle concentrations of the St. Lawrence River (Caron et al. 2007) and of US surface waters which range from $10^{2}$ to $10^{6}$ particles $/ \mathrm{mL}$ (McTigue et al. 1998). To allow a direct comparison of the microsphere removal in presence and in absence of clay particles, the range of microsphere concentrations tested in absence of kaolinite was adjusted to correspond to 
the total particles injected in experiments conducted with kaolinite. In this study, the lowest tested microsphere concentration $\left(10^{2} / \mathrm{mL}\right)$ was selected to allow precise filter effluent microsphere measurements and to minimize the uncertainty in removal calculations, albeit it is higher than the naturally occurring Cryptosporidium concentrations at the Atwater and Charles-J. Des Baillets water intakes $(\sim 0.01$ to 10 oocysts/L). Thus, the experimental design allows the assessment of the co-transport behavior of microspheres (MS) and kaolinite particles (K) and its impact on filter performance as a function of the dominant particle nature (MS versus K).

Table 1. Experimental design.

\begin{tabular}{cccc}
\hline \multirow{2}{*}{ Experiment } & \multicolumn{3}{c}{ Influent concentration $\left(\mathrm{mL}^{-1}\right)$} \\
\cline { 2 - 4 } & $\begin{array}{c}\text { Microspheres } \\
(\mathrm{MS})\end{array}$ & $\begin{array}{c}\text { Kaolinite particles } \\
(\mathrm{K})\end{array}$ & $\begin{array}{c}\text { Total particles } \\
(\mathrm{TP})\end{array}$ \\
\hline M1 & $10^{2}$ & 0 & $10^{2}$ \\
M2 & $10^{4}$ & 0 & $10^{4}$ \\
M3 & $10^{6}$ & 0 & $10^{6}$ \\
K1 & $10^{2}$ & $10^{4}$ & $10^{4}$ \\
K2 & $10^{2}$ & $10^{6}$ & $10^{6}$ \\
\hline
\end{tabular}

\section{Tracer experiments}

Tracer experiments were carried out prior and subsequent to a filtration experiment conducted with the highest kaolinite load $\left(10^{6} \mathrm{~K} / \mathrm{mL}\right)$ to assess the impact of particle deposition on the filter bed porosity. Influent and effluent bromide tracer concentrations were measured according to the Phenol Red Colorimetric Method 4500Br-B (American Public Health Association et al. 2005).

\section{Spatial distribution of retained microspheres}

Subsequent to column elution (deloading; $32 \mathrm{PVs}$ ), the filter bed of the first column replicate was sampled by filter coring at 6 fractional depths of 5\%, 7.5\%, 20\%, 40\%, $60 \%, 75 \%$ (starting from the column inlet) to assess the spatial distribution of retained microspheres. Samples were placed in synthetic water and rocked end-to-end (Rocker II, Biokel Scientific) for 15 minutes. The supernatant was immediately removed for microsphere enumeration as described previously.

\section{Mass balance}

To assess the recovery of filter coring experiments, a mass balance was calculated subsequent to each experiment as described below:

$$
\begin{aligned}
& N_{\text {influent }}=t C_{0} Q \text { or } N_{\text {effluent }}+N_{\text {filter bed }} \\
& N_{\text {effluent }}=\sum_{i=1}^{32} V_{P V}\left(\frac{C_{i}+C_{i+1}}{2}\right)
\end{aligned}
$$




$$
\begin{aligned}
N_{\text {filter bed }}=( & 0.05 S_{0.05}+0.025\left(\frac{S_{0.05}+S_{0.075}}{2}\right)+0.125\left(\frac{S_{0.075}+S_{0.2}}{2}\right)+0.2\left(\frac{S_{0.2}+S_{0.4}}{2}\right)+ \\
& \left.0.2\left(\frac{S_{0.4}+S_{0.6}}{2}\right)+0.15\left(\frac{S_{0.6}+S_{0.75}}{2}\right)+0.25 S_{0.75}\right) \times M_{t}
\end{aligned}
$$

where $t$ is the duration of continuous microsphere injection, $C_{0}$ the mean influent concentration of suspended microspheres, $Q$ the flow rate, $V_{\mathrm{pv}}$ the volume of water per $\mathrm{PV}, C_{\mathrm{i}}$ the effluent concentration of suspended microspheres at pore volume $i, S$ the number of microspheres per gram of dry sand at a given fractional depth, and $M_{\mathrm{t}}$ the total mass of dry sand contained in the column. The recovery of the microsphere extraction $(\%)$ was calculated as described below:

Recovery $_{\text {filter bed }}=\frac{N_{\text {filter bed }}}{\left(N_{\text {influent }}-N_{\text {effluent }}\right)} \times 100$

\section{Calculation of particle deposition rates}

To quantitatively compare results obtained from filtration experiments, the microsphere deposition rate coefficient $\left(k_{\mathrm{d}}\right)$ was calculated for each filtration experiment as described below (Yao et al. 1971; Tufenkji \& Elimelech 2004).

$k_{d}=-\frac{v}{L} \ln \left(\frac{C}{C_{0}}\right)$

where $L$ is the total filter bed length, $v$ is the porewater velocity, $C / C_{0}$ the normalized microsphere effluent concentration determined by numerically integrating the breakthrough curves (BTCs). The number of retained microspheres at a given depth, $S(x)$, is described by the classical colloid filtration theory (CFT) as follows:

$S(x)=\frac{t \theta k_{d} C_{0}}{\rho_{b}} \exp \left(\frac{k_{d}}{v} x\right)$

where $t$ is the duration of the continuous microsphere injection, $\theta$ the bed porosity, $\rho_{\mathrm{b}}$ the media bulk density, and $x$ the column depth.

\section{Results and Discussion}

\section{Tracer experiments}

Tracer BTCs remained unchanged subsequent to a filtration experiment conducted with $10^{6} \mathrm{~K} / \mathrm{mL}$ (results not shown), indicating that addition of kaolinite did not significantly change the apparent porosity of the filter bed. In addition, head loss remained low and stable throughout all tested conditions (results not shown). Thus, the observed microsphere BTCs were assessed during stable filter operation. 


\section{Impact of influent kaolinite and Cryptosporidium-sized microsphere concentration on filter performance}

Influent microsphere (MS) and kaolinite particle (K) concentrations largely impacted the removal of microspheres. The results of filtration experiments are presented in terms of normalized microsphere effluent concentrations $\left(C / C_{0}\right)$ to take into account the various tested microsphere concentrations as defined by the experimental design and to allow a comparison of the resulting BTCs (Figure 1). Firstly, the BTCs of experiments conducted with $10^{2}$ or $10^{4}$ total particles $/ \mathrm{mL}$ (Figure 1A, 1B) demonstrate that experiments were conducted at steady state as the effluent microsphere concentration reached a plateau before sharply decreasing during the elution phase. Secondly, filter performance decreased as the influent microsphere concentration increased from $10^{2}$ to $10^{6}$ per $\mathrm{mL}$ without kaolinite. The BTCs of experiments conducted with $10^{6} \mathrm{MS} / \mathrm{mL}$ clearly illustrate this decreased performance with time as the normalized effluent microsphere concentration increased throughout the microsphere injection period (Figure 1C). It can also be noted that dosing $10^{4} \mathrm{~K} / \mathrm{mL}+10^{2} \mathrm{MS} / \mathrm{mL}$ had a minor impact on microsphere removal. However, dosing $10^{6} \mathrm{~K}+10^{2} \mathrm{MS} / \mathrm{mL}$ improved $\mathrm{MS}$ removal compared to the reference condition $\left(10^{2} \mathrm{MS} / \mathrm{mL}\right.$ without kaolinite). In fact, the normalized effluent microsphere concentration decreased throughout the duration of particle injection (Figure 1C). Finally, for comparative purposes, we evaluated the deposition rate coefficient $\left(k_{\mathrm{d}}\right)$ for every tested condition (Table 2). Here, $k_{\mathrm{d}}$ serves as an indicator of the initial filtration performance of the system but does not take into account the time-dependent mechanisms involved. This is of importance as $k_{\mathrm{d}}$ does not fully highlight the increased filtration performance with time in the presence of $10^{6} \mathrm{~K} / \mathrm{mL}$ nor does it reveal the extent of the significant decrease of performance at the high concentration of microspheres $\left(10^{6} \mathrm{MS} / \mathrm{mL}\right)$ without kaolinite.
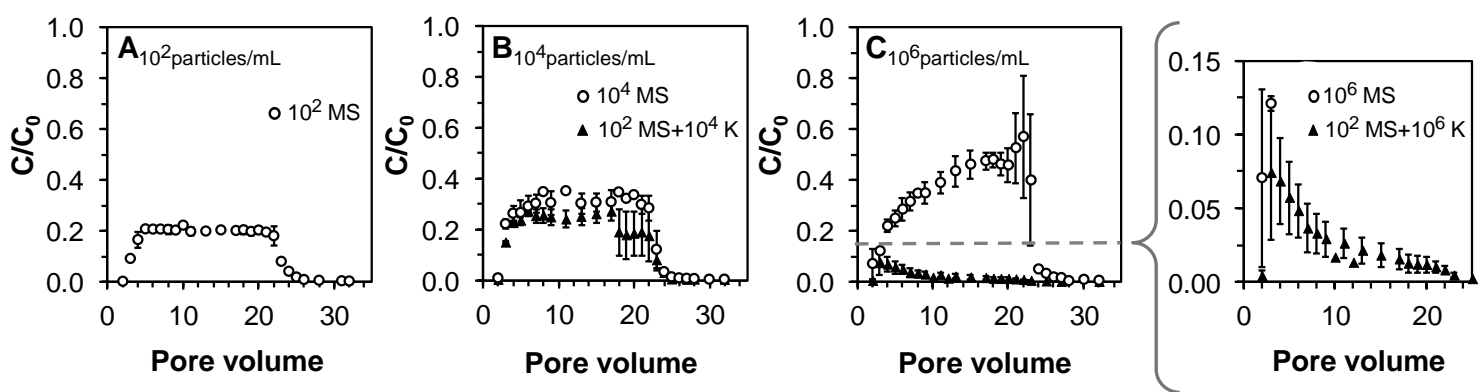

Figure 1. Comparison of microsphere (MS) breakthrough curves of filtration experiments conducted with a total particulate load of (A) $10^{2}$ particles $/ \mathrm{mL}$, (B) $10^{4}$ particles $/ \mathrm{mL}$, and (C) $10^{6}$ particles $/ \mathrm{mL}$ in absence (open circles) or presence (solid triangles) of kaolinite particles (K). Error bars represent minimum and maximum values of duplicate experiments.

The interactions between particles are key to understanding the microsphere-kaolinite cotransport behavior. Due to the negative charge of microspheres, microsphere-microsphere interactions are unfavorable and thus the experimental design of the current study is favorable to blocking. In fact, the observed decreased microsphere removal with increasing influent microsphere concentrations can be attributed to blocking. This is 
clearly depicted by the BTCs of experiments conducted with $10^{6} \mathrm{MS} / \mathrm{mL}$ where the normalized microsphere effluent concentration $\left(C / C_{0}\right)$ increased throughout the microsphere injection. This observation corroborates previous studies that have associated this behavior to blocking of favorable attachment sites (Camesano \& Logan 1998; Bradford \& Bettahar 2006). In contrast, the addition of kaolinite in the influent water increased microsphere removal in a time-dependent manner. Consequently, kaolinite-microsphere interactions were favorable despite the fact that both particles possessed a negative zeta potential. This is in agreement with previously reported observations made in glass bead columns where the presence of kaolinite increased Pseudomonas putida retention (Vasiliadou \& Chrysikopoulos 2011). In the current study, the increased filter performance in presence of kaolinite particles is attributable to (i) media ripening and (ii) microsphere-kaolinite heteroaggregation in influent water. Firstly, media ripening is clearly illustrated by the BTCs of experiment K2 (Figure 1C) whereby the normalized microsphere effluent concentration $\left(C / C_{0}\right)$ decreased with time. This observation is in agreement with previous reports where this type of BTC profile has been attributed to media ripening due to favorable particle-particle interactions (Camesano \& Logan 1998). This also corroborates with previously reported observations made in batch reactors where the addition of kaolinite in influent water increased oocyst removal (Gitis et al. 2002). Moreover, it is in agreement with an earlier study where the predeposition of bentonite clay particles onto collectors decreased the zeta potential of sand grains which increased the retention of incoming bacteria (Yang et al. 2012). Secondly, the increased retention may also be a result of heteroaggregation of suspended microspheres and suspended kaolinite leading to physical straining of these aggregates. This is likely because at higher kaolinite concentrations, a greater proportion of influent particles have a size resulting in particle-to-collector size ratios above the threshold value for straining $\left(d_{\mathrm{p}} / d_{\mathrm{c}}>0.005\right)$ (Bradford et al. 2006) in comparison to the kaolinite suspensions in synthetic water without microspheres $\left(10^{6} \mathrm{~K} / \mathrm{mL} ; 5 \%\right.$, $10^{2} \mathrm{MS}+10^{4} \mathrm{~K} / \mathrm{mL} ; 10 \%$ and $10^{2} \mathrm{MS}+10^{6} \mathrm{MS} / \mathrm{mL} ; 29 \%$ ) (Figure 2). Moreover, because kaolinite particles are denser than microspheres, heteroaggregation may also lead to increased microsphere transport by sedimentation (Searcy et al. 2005) to the vicinity of collector (sand) grains resulting in greater removal. This assumption corroborates the observed increased $P$. putida deposition on glass beads in presence of kaolinite (Vasiliadou \& Chrysikopoulos 2011), enhanced Cryptosporidium retention on quartz sand in presence of illite clay (Park et al. 2012) and increased removal due to the codeposition of bacteria and bentonite clay (Yang et al. 2012). Lastly, the reported greater microsphere retention as a function of kaolinite load in this investigation corroborates previous observations made with regards to the co-transport of bacteria and clay (Vasiliadou \& Chrysikopoulos 2011; Yang et al. 2012). 


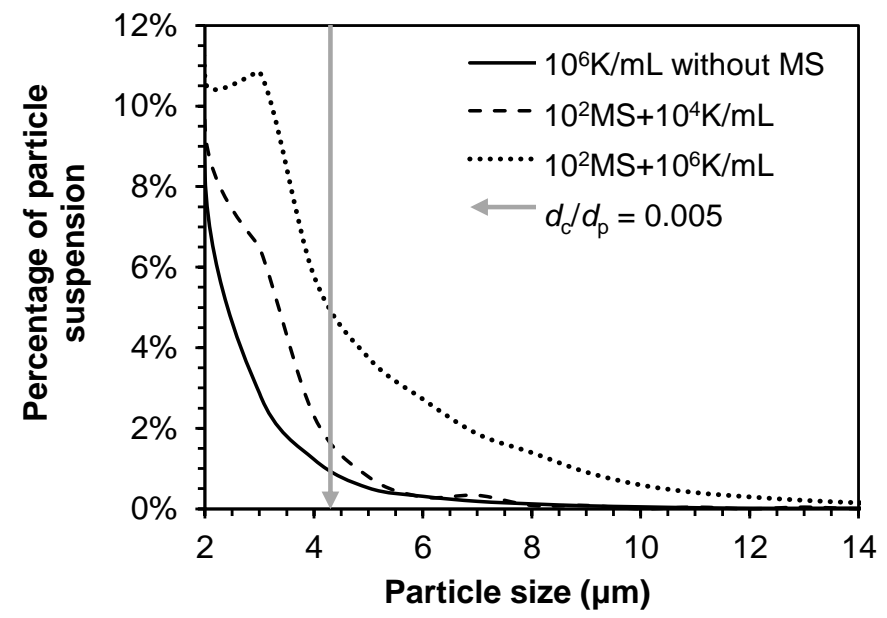

Figure 2. Influent particle size distribution of microsphere (MS) and kaolinite particle (K) suspensions of $10^{6} \mathrm{~K} / \mathrm{mL}$ without MS (bold line), $10^{2} \mathrm{MS}+10^{4} \mathrm{~K} / \mathrm{mL}$ (dotted line) and $10^{2} \mathrm{MS}+10^{6} \mathrm{~K} / \mathrm{mL}$ (dashed line). The arrow indicates the critical particle-to-collector size ratio $\left(d_{\mathrm{p}} / d_{\mathrm{c}}\right)$ of 0.005 (Bradford et al. 2006).

Kaolinite is a two layer mineral clay composed of silica and alumina layers where the hydroxyl-terminated edges possess amphoteric sites (Tombácz \& Szekeres 2006). The basal plane represents most of the surface area of these particles whereas edges represent only $7 \%$ to $14 \%$ of the total surface (Zhou \& Gunter 1992). In the tested conditions $(\mathrm{pH}=8.2)$, the basal plane should be negatively charged whereas the edges should be positively charged which may, in turn, adsorb to the negatively charged carboxylate groups (Jiang et al. 2010) located on the surface of microspheres. Consequently, we hypothesize that the presence of these amphoteric sites may explain the favorable interactions between microspheres and kaolinite. Thus, as observed in packed columns with scanning electron microscopy images (Vasiliadou \& Chrysikopoulos 2011) and suggested in batch reactors (Gitis et al. 2002), we propose that the kaolinite particles attach onto the sand grains and subsequently, microspheres are retained by the deposited kaolinite particles. This hypothesis also explains the observed BTC profiles and the enhanced microsphere removal due to kaolinite addition. Thus, results of the current investigation demonstrate that the reported increased microbial retention in packed columns in presence of clay particles could also occur in engineered systems even if rapid granular filters are operated at higher flow rates and use heterogeneous granular media. Although the microsphere concentrations tested in this investigation exceed typical Cryptosporidium concentrations in source waters, the enhanced performance due to the clay induced media ripening observed in this study is most likely still applicable to lower microbial concentrations as it is driven by the influent kaolinite concentration.

\section{Mass balance of filter coring}

Filter coring was used to assess the number of retained microspheres in the filter bed following the filtration experiments. The experimental protocol was proven to be appropriate by the high recoveries (mean $=85 \% \pm 14 \%$ ) of filter coring experiments 
(Table 2). These reported recoveries were used to correct the measured retained microsphere profiles of each tested condition (Figure 3). Nonetheless, some uncertainty in mass balance calculations may have been induced by the evaluation of the fraction of retained microspheres within the filter bed. This inaccuracy is most probably attributable to the small mass per sample (mean $\pm \mathrm{SD}=0.22 \% \pm 0.05 \%$ ) extracted by filter coring in comparison to the total mass of the filter bed.

Table 2. Deposition rate coefficient $\left(k_{\mathrm{d}}\right)$ of filtration experiments and mass balance of filter coring experiments.

\begin{tabular}{lcccc}
\hline \multirow{2}{*}{ Condition } & \multirow{2}{*}{$k_{\mathrm{d}}\left(\mathrm{s}^{-1}\right)$} & \multicolumn{3}{c}{ Mass balance } \\
\cline { 3 - 5 } & & Effluent & Filter bed & Total $\dagger$ \\
\hline $10^{2} \mathrm{MS} * / \mathrm{mL}$ & 0.0087 & $19 \%$ & $44 \%$ & $63 \%$ \\
$10^{4} \mathrm{MS} / \mathrm{mL}$ & 0.0065 & $35 \%$ & $68 \%$ & $103 \%$ \\
$10^{6} \mathrm{MS} / \mathrm{mL}$ & 0.0046 & $52 \%$ & $35 \%$ & $87 \%$ \\
$10^{2} \mathrm{MS} / \mathrm{mL}+10^{4} \mathrm{~K}^{\S} / \mathrm{mL}$ & 0.0079 & $19 \%$ & $69 \%$ & $88 \%$ \\
$10^{2} \mathrm{MS} / \mathrm{mL}+10^{6} \mathrm{~K} / \mathrm{mL}$ & 0.0193 & $4 \%$ & $80 \%$ & $84 \%$ \\
\hline
\end{tabular}

*MS- Microspheres

$\S \mathrm{K}$ - Kaolinite particles

$\dagger$ Total- Sum of recovery (effluent and filter bed)

\section{Microsphere retention profiles}

The microsphere retention profiles (Figure 3) corrected for the specific recovery of microspheres according to the mass balance calculations (63\% to $103 \%)$ differed from one tested condition to another and particularly so in the top layer of the filter bed (0-20\% deep, $15 \mathrm{~cm}$ from the inlet). As the influent microsphere concentration increased, the fraction of total retained microspheres within the top layer of the filter bed decreased $\left(10^{2} \mathrm{MS} / \mathrm{mL} ; 41.3 \pm 1.1 \%, 10^{4} \mathrm{MS} / \mathrm{mL} ; 28.4 \pm 0.4 \%\right.$ and $\left.10^{6} \mathrm{MS} / \mathrm{mL} ; 22.2 \pm 0.9 \%\right)$. When the influent kaolinite load increased to $10^{4} \mathrm{~K} / \mathrm{mL}$, the fraction of total retained microspheres in the top layer of the filter bed somewhat increased $(44.2 \pm 0.2 \%)$ in relation to the reference condition $\left(10^{2} \mathrm{MS} / \mathrm{mL}\right.$ without kaolinite). In contrast, when the clay load was increased to $10^{6} \mathrm{~K} / \mathrm{mL}$, the fraction of total retained microspheres in the same layer decreased $(32.4 \pm 0.3 \%)$ in relation to the reference condition $\left(10^{2} \mathrm{MS} / \mathrm{mL}\right.$ without kaolinite).

Observed microsphere retention profiles were not always well described by predictions based on the classical CFT which considers the "clean-bed" removal of particles characterized by first-order deposition kinetics resulting in an exponential decay of suspended and retained particles with distance. Some discrepancies between observed and predicted retention profiles were expected as all experiments were conducted under unfavorable conditions for microsphere deposition (low ionic strength and high $\mathrm{pH}$ ) (Li et al. 2004; Tufenkji \& Elimelech 2005). In addition, classical CFT does not take into account dynamic removal mechanisms such as blocking and ripening (Ryan \& Elimelech 1996). Although the collected data point to time-dependent and depth-dependent mechanisms such as filter ripening and blocking, the limited data set does not provide 
sufficient information to comprehensively model these complex processes; namely, only one experimental condition led to blocking (Figure 1C, MS without K), and only one experimental condition led to ripening (Figure 1C, MS+K). Despite this limitation, the predicted retention profiles based on classical CFT were included here for comparative purposes as it is interesting to compare observed and predicted retention profiles as a function of the dominant particle (MS versus $\mathrm{K}$ ). In fact, $k_{\mathrm{d}}$ should provide only an accurate description of clean-bed performance and thus, in this study, would theoretically better describe filtration experiments that do not exhibit second-order deposition kinetics (Figure 1A and 1B). Because the calculated deposition rate coefficient $\left(k_{\mathrm{d}}\right)$ impacts $S(x)$ calculations, predicted retention profiles should theoretically be less accurate for filtration experiments conducted with a particulate load of $10^{6}$ particles $/ \mathrm{mL}$ where ripening and blocking are noticeably prevailing. However, the observed retention profiles exceeded predictions of the classical CFT at the lower particulate loads and did so more importantly in the top layer of the filter bed (Figure 3A and 3B). It is interesting to note that the fraction of total retained microspheres in the top layer of the filter bed decreased with increasing influent microsphere concentration. This is of particular interest as it illustrates that the favorable attachment sites were saturated in the top layer and that blocking occurred to a greater extent with increasing microsphere concentration. Contrary to expectation, the retention profile of the filtration experiment conducted with a particulate load of $10^{6} \mathrm{~K} / \mathrm{mL}$ was better described by the classical CFT despite the fact that $k_{\mathrm{d}}$ calculations were biased by the time-dependent removal of microspheres. We hypothesize that this unexpected observation is an outcome of media ripening for which the deposited kaolinite particles created new attachment sites which in turn resulted in more favorable conditions for microsphere deposition. Finally, the spatial distribution of kaolinite was not assessed in the current study, but should be considered in future research. Moreover, ongoing research should also investigate whether kaolinite particle accumulation on collector grains increases media roughness and induces greater microsphere retention.
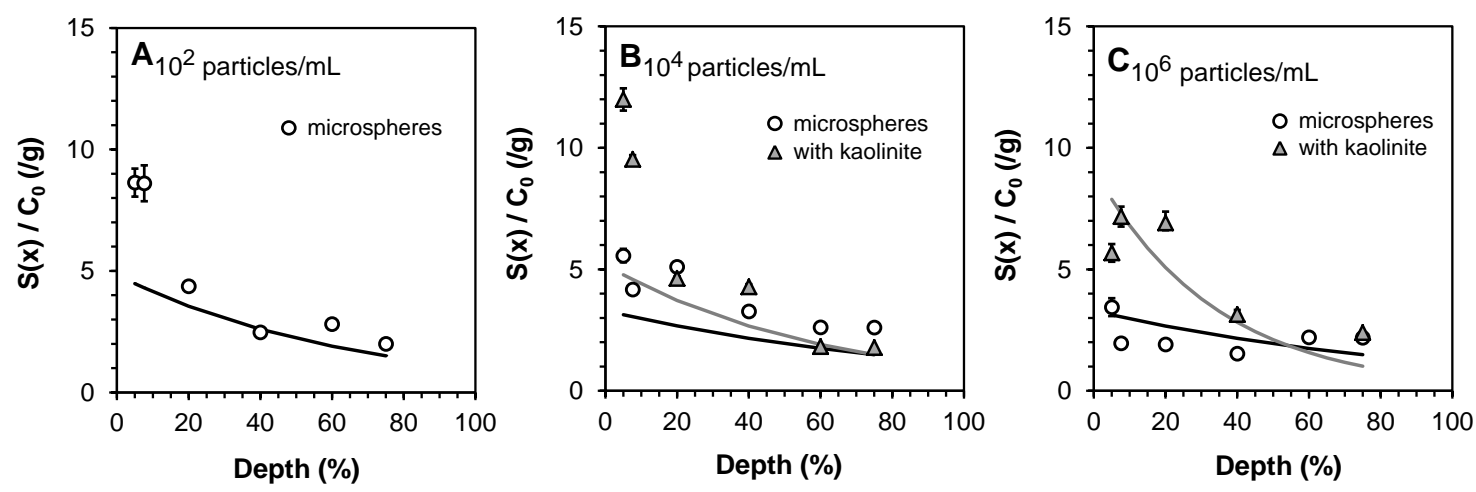

Figure 3. Measured retained microsphere concentration profiles of filtration experiments conducted with a total influent particulate load of (A) $10^{2}$ particles $/ \mathrm{mL}$, (B) $10^{4}$ particles $/ \mathrm{mL}$ and (C) $10^{6}$ particles/mL in absence (open circles) or presence (solid grey triangles) of kaolinite. The presented data were adjusted according to the recovery rate of the extraction protocol of every tested condition. Bold lines represent predicted values according to the classical CFT of experiments conducted with kaolinite (grey) and without kaolinite (black). Error bars represent minimum and maximum values. 


\section{Implications for the water industry}

Results obtained in this study clearly demonstrate that excessive dosage of microspheres in absence of coagulation and other particles may not be representative of reality as different removal mechanisms can come into play. Experiments conducted with excessive influent oocyst or surrogate concentrations may overestimate filter performance in presence of coagulation (Assavasilavasukul et al. 2008) or underestimate filter performance in absence of coagulation (this study). Therefore, results of such experiments should be interpreted with caution. Taking into account the limitations of this study (i.e., the appropriateness of microspheres as Cryptosporidium surrogate), the trends observed suggest that WTPs without coagulation and fed with low turbidity water might suffer from lower Cryptosporidium removal by filtration. More research is needed to integrate the impact of source water quality on sedimentation and filtration performances in order to identify conditions where Cryptosporidium and Giardia removal credits attributed to filtration processes differ from the true performances. Monitoring of surrogate organisms such as bacterial endospores might be an appropriate solution to evaluate treatment performance as their removal has been found to be correlated with Cryptosporidium removal (Jaidi et al. 2009).

\section{Conclusions}

In conclusion, the results of this investigation reveal that microsphere removal is impaired at high influent concentrations due to blocking, whereas filter performance improves when the influent suspension is dominated by kaolinite as it results in media ripening. We suggest that this enhanced performance is attributable to favorable microsphere-kaolinite interactions. This research demonstrates that, in absence of coagulation, when a high dose of microorganisms or surrogates is spiked in source water to maximize recovery in filter effluent, the resulting treatment performance evaluation might underestimate the actual performance due to "artificial" blocking caused by microsphere interference. Moreover, this investigation suggests that granular media filters fed by low turbidity uncoagulated waters will suffer from lower removal of Cryptosporidium. Future work should evaluate whether the latter conclusion can be extended to engineered systems using coagulation.

\section{Acknowledgements}

This research was supported by the Industrial-NSERC Chair in Drinking Water Treatment whose industrial partners include the City of Montreal, John Meunier Inc., and the City of Laval. The authors wish to thank the Chair's personnel for their technical assistance in the laboratory work and I.R. Quevedo (McGill) for assistance with electrophoretic mobility measurements. The authors also acknowledge the financial support of the Canadian Water Network and the Canada Research Chairs program. 


\section{References}

American Public Health Association, American Water Works Association \& Water Environment Federation, 2005. Standard methods for the examination of water and wastewater (21 th Edition), Washington, DC, USA.

Assavasilavasukul, P., Harrington, G.W., Lau, B.L.T., Hoffman, R.M. \& Borchardt, M.A., 2008. Effect of pathogen load on pathogen removal by conventional treatment. 91221, Denver, Colorado, USA.

Bradford, S.A. \& Bettahar, M., 2006. Concentration dependent transport of colloids in saturated porous media. Journal of Contaminant Hydrology, 82 (1-2),99-117.

Bradford, S.A., Simunek, J., Bettahar, M., van Genuchten, M.T. \& Yates, S.R., 2006. Significance of straining in colloid deposition: evidence and implications. Water Resources Research, 42 (12),1215.

Camesano, T.A. \& Logan, B.E., 1998. Influence of fluid velocity and cell concentration on the transport of motile and nonmotile bacteria in porous media. Environmental Science and Technology, 32 (11),1699-1708.

Caron, É., Chevrefils Jr., G., Barbeau, B., Payment, P. \& Prévost, M., 2007. Impact of microparticles on UV disinfection of indigenous aerobics spores. Water Research, 41 (19),45464556.

Chrysikopoulos, C.V. \& Syngouna, V.I., 2012. Attachment of bacteriophages MS2 and PhiX174 onto kaolinite and montmorillonite: extended-DLVO interactions. Colloids and Surfaces B:Biointerfaces, 92),74-83.

Emelko, M.B., Huck, P.M. \& Coffey, B.M., 2005. A review of Cryptosporidium removal by granular media filtration. Journal of the American Water Works Association, 97 (12),101-115.

Gaskin, S.J., Pieterse, J., Shafie, A.A. \& Lepage, S., 2003. Erosion of undisturbed clay samples from the banks of the St. Lawrence River. Canadian Journal of Civil Engineering, 30 (3),585-595.

Gauthier, V., Barbeau, B., Tremblay, G., Millette, R. \& Bernier, A.-M., 2003. Impact of raw water turbidity fluctuations on drinking water quality in a distribution system. Environmental Engineering and Science, 2 (4),281-291.

Gitis, V., Haught, R.C., Clark, R.M. \& Rothenberg, G., 2002. Assessing the removal of inorganic colloids and Cryptosporidium parvum from drinking water. Journal of Environmental Monitoring, 4 (2),244-248.

Jaidi, K., Barbeau, B., Carrière, A., Desjardins, R. \& Prévost, M., 2009. Including operational data in QMRA model: development and impact of model inputs. Journal of Water and Health, 7 (1),7795.

Jiang, T., Hirasaki, G.J. \& Miller, C.A., 2010. Characterization of kaolinite $\zeta$ potential for interpretation of wettability alteration in diluted bitumen emulsion separation. Energy and Fuels, 24 (4),2350-2360.

Lake, I.R., Bentham, G., Kovats, R.S. \& Nichols, G.L., 2005. Effects of weather and river flow on Cryptosporidiosis. Journal of Water and Health, 3 (4),469-474.

Li, X., Scheibe, T.D. \& Johnson, W.P., 2004. Apparent decreases in colloid deposition rate coefficients with distance of transport under unfavorable deposition conditions: a general phenomenon. Environmental Science and Technology, 38 (21),5616-5625.

McTigue, N.E., LeChevallier, M., Arora, H. \& Clancy, J., 1998. National assessment of particle removal by filtration. 90757 , Denver, Colorado, USA. 
Park, Y., Atwill, E.R., Hou, L., Packman, A.I. \& Harter, T., 2012. Deposition of Cryptosporidium parvum oocysts in porous media: a synthesis of attachment efficiencies measured under varying environmental conditions. Environmental science \& technology, 46 (17),9491-9500.

Ryan, J.N. \& Elimelech, M., 1996. Colloid mobilization and transport in groundwater. Colloids and Surfaces A: Physicochemical and Engineering Aspects, 107),1-56.

Searcy, K.E., Packman, A.I., Atwill, E.R. \& Harter, T., 2005. Association of Cryptosporidium parvum with suspended particles: impact on oocyst sedimentation. Applied and Environmental Microbiology, 71 (2),1072-1078.

Tombácz, E. \& Szekeres, M., 2006. Surface charge heterogeneity of kaolinite in aqueous suspension in comparison with montmorillonite. Applied Clay Science, 34 (1-4),105-124.

Tufenkji, N., Dixon, D.R., Considine, R. \& Drummond, C.J., 2006. Multi-scale Cryptosporidium/sand interactions in water treatment. Water Research, 40 (18),3315-3331.

Tufenkji, N. \& Elimelech, M., 2004. Correlation equation for predicting single-collector efficiency in physicochemical filtration in saturated porous media. Environmental Science and Technology, 38 (2),529-536.

Tufenkji, N. \& Elimelech, M., 2005. Breakdown of colloid filtration theory: role of the secondary energy minimum and surface charge heterogeneities. Langmuir, 21 (3),841-852.

Vasiliadou, I.A. \& Chrysikopoulos, C.V., 2011. Cotransport of Pseudomonas putida and kaolinite particles through water-saturated columns packed with glass beads. Water Resources Research, 47 (2),W02543 (02541-02514).

World Health Organization, 2006. Guidelines for drinking water quality. Cryptosporidium.

Yang, H., Tong, M. \& Kim, H., 2012. Influence of bentonite particles on representative gram negative and gram positive bacterial deposition in porous media. Environmental science \& technology, 46 (21),11627-11634.

Yao, K.-M., Habibian, M.T. \& O'Melia, C.R., 1971. Water and waste water filtration: concepts and applications. Current Research, 5 (11),1105-1112.

Zhou, Z. \& Gunter, W.D., 1992. The nature of the surface charge of kaolinite. Clays and Clay Minerals, 40 (3),365-368. 